12 - ORIGINAL ARTICLE

ISCHEMIA-REPERFUSION

\title{
Effects of hyperbaric oxygen therapy as hepatic preconditioning in rats submitted to hepatic ischemia/reperfusion injury ${ }^{1}$
}

\author{
Daniele Moraes Losada', Agnaldo Bruno Chies ${ }^{\mathrm{II}}$, Omar Feres ${ }^{\mathrm{III}}$, Eleazar Chaib ${ }^{\mathrm{IV}}$, Luiz Augusto Carneiro D'Albuquerque \\ Orlando Castro-e-Silva ${ }^{\mathrm{VI}}$
}

DOI: http://dx.doi.org/10.1590/S0102-8650201400140012

IUndergraduate of medicine Marilia Faculty of Medicine, FAMEMA, Marília/SP: Acquisition and interpretation of data; Responsible for manuscript preparation. Manuscript writing; Responsible for English language.

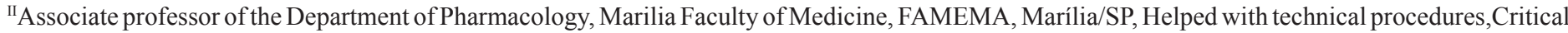
revision.

IIIAssociate professor of Ribeirão Preto Medical School, University of São Paulo, Critical revision

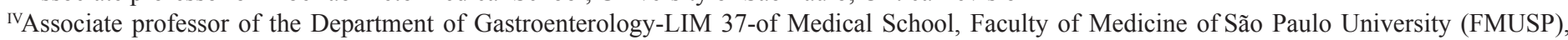
Brazil - Critical revision.

${ }^{\vee}$ Full professor of the Department of Gastroenterology of Medical School, Faculty of Medicine of São Paulo University (FMUSP), Brazil - Critical revision. ${ }^{\mathrm{v}}$ Full professor of Department Surgery and Anatomy. Responsible for intellectual and scientific content of the study; Supervised all phases of study. Collection and precessing of study. Critical revision.

\section{ABSTRACT}

PURPOSE: To analyze the role of hyperbaric oxygen therapy as hepatic preconditioning in rats submitted to hepatic ischemia and reperfusion.

METHODS: Wistar rats were randomly divided into three groups: SHAM, rats submitted to surgical stress without hepatic ischemia and reperfusion, I/R, rats submitted to total hepatic pedicle ischemia for $30 \mathrm{~min}$, followed by $5 \mathrm{~min}$ of reperfusion; HBOI/R, rats submitted to 60 minutes of hyperbaric oxygen therapy at $2 \mathrm{~atm}$ and immediately submitted to the experimental protocol of ischemia and reperfusion. Liver function was assessed by measuring serum alanine aminotransferase and aspartate aminotransferase, as well as mitochondrial function by determining states 3 and 4 of mitochondrial respiration, respiratory control rate and mitochondrial permeability transition (mitochondrial swelling). The results were analyzed by the Mann-Whitney test and all P-values $<0.05$ were considered significant.

RESULTS: There were significant differences in serum aspartate aminotransferase values in groups SHAM vs. HBOI/R, I/R vs HBOI/R, alanine aminotranferase in groups SHAM and I/R; State 3 in SHAM groups vs. I/R, SHAM vs. HBOI/R, State 4 in I/R vs HBOI/R groups, respiratory control rate in SHAM vs I/R groups; mitochondrial swelling in SHAM vs. I/R groups, and SHAM vs HBOI/R.

CONCLUSION: Hyperbaric preconditioning improved hepatic mitochondrial function and decreased serum markers of liver injury in the ischemia and reperfusion process.

Key words: Hyperbaric oxygenation. Mitochondria. Liver. Ischemia. Reperfusion. 


\section{Introduction}

Hyperbaric oxygen (HBO) therapy is indicated in some disorders such as decompression sickness, gas embolism and carbon monoxide poisoning since it increases the partial pressure of oxygen in plasma in molecules dissolved in it, and also increases the saturation of circulating hemoglobin ${ }^{1}$.

HBO appears to improve other conditions both in animals and in human beings, especially when pathophysiology events occur such as hypoxia, ischemia and reperfusion ${ }^{2-3}$

It is known that the ischemia and reperfusion process, experienced in various clinical conditions/surgeries such as transplants ${ }^{4}$, causes serious local and systemic damage, especially during reperfusion due to exacerbation of oxidative stress promoted mainly by the large quantity of neutrophils migrating toward the ischemic organ ${ }^{5-8}$. Despite its relevance, this issue is the source of many controversies in favor of ${ }^{9-10}$ and against ${ }^{11}$ the association between $\mathrm{HBO}$ and ischemia and reperfusion. Such controversies are mainly due to a lack of studies that explore the basic biochemical aspects of this association ${ }^{4,12}$.

In this respect, hypoxia is the main factor triggering injury processes in the ischemic phase ${ }^{13}$. After interrupting $\mathrm{HBO}$, the partial pressure of oxygen in serum rapidly falls. However, the tissue pressure of this gas can remain elevated for up to several hours depending on the tissue and exposure time ${ }^{14-17}$. Therefore, we have assumed that hyperbaric preconditioning would decrease the suffering of the hypoxic liver tissue, attenuating the biochemical cascade of ischemic injury and thus promoting a lower inflammatory response with lower content of neutrophils in the reperfusion process and greater tissue preservation. We have also questioned whether hyperoxia itself favors an increase of local oxidative stress at two times, i.e., in the pre-ischemic and the ischemic phase, which would promote cell damage and hence injury due to ischemia and hepatic reperfusion.

We adopted mitochondrial function as a parameter because it is widely used scientifically as a reference area of hepatic tissue preservation after I/R injury ${ }^{13,18}$. Therefore our aim is to analyze the role of hyperbaric oxygen therapy as hepatic preconditioning in rats submitted to hepatic ischemia and reperfusion.

\section{Methods}

Twenty four male Wistar rats weighing 200 to $300 \mathrm{~g}$ were randomized into 3 groups: SHAM - rats submitted to surgical stress without exposure to $\mathrm{HBO}$ and without hepatic pedicle clamping, I/R - rats submitted to $30 \mathrm{~min}$ of ischemia followed by 5 min of reperfusion without $\mathrm{HBO}$ exposure; HBOI/R - rats submitted to $60 \mathrm{~min}$ of $\mathrm{HBO}$ at 2 absolute atmospheres (ATA) and immediately submitted to $30 \mathrm{~min}$ of ischemia followed by 5 min of reperfusion. The animals had free access to laboratory chow (Purina Nutrimentos Ltda.) and water. The rats were kept at the animal house of FMRP-USP at room temperature on a 12hour light-dark cycle according to the guidelines of the Ethics Committee for Animal Experimentation of FMRP-USP.

\section{Operation techniques}

Clean and sterilized surgical materials were used in a standardized way. The animals were anesthetized with a xylazine hydrochloride solution $(20 \mathrm{mg} / \mathrm{ml})$ and ketamine hydrochloride $(50 \mathrm{mg} / \mathrm{ml})$ at a $1: 2$ ratio and at a dose of $100 \mathrm{mg} / \mathrm{kg} /$ weight. The anesthetic was applied to the right superficial gluteal muscle. The surgical procedure began with medial laparotomy which extended from the lower third of the xiphoid process to the pubis, followed by exploration of the abdominal cavity and delicate dissection of the round ligament of the liver and identification of the hepatic pedicle. Total hepatic pedicle clamping was carried out for 30 minutes using a home-made clamp. The rat was then submitted to 5 minutes of reperfusion. The animal was sacrificed by total exsanguination of the inferior vena cava soon after its exposure, with manipulation of the abdominal viscera.

\section{Hyperbaric oxygen therapy}

HBO was applied in a collective chamber (simultaneous exposure of 4 rats) (Sechrist model 2500 B) directly pressurized with oxygen. Each session lasted 60 minutes: 15 minutes for compression and 15 minutes for decompression inside the chamber. Hence, the animals underwent 30 minutes of continuous $\mathrm{HBO}$ at 2 ATA. Exposure to presurgical HBO was performed at the same time of day.

\section{Liver function}

Liver function was determined based on the determination of blood (alanine aminotranferase - ALT, aspartate aminotransferase - AST) (19) and tissue parameters (liver median lobe samples were collected after exactly 5 minutes of reperfusion when the animal was sacrificed) Next, the animals were sacrificed for analysis of the following parameters of mitochondrial function: states 3 and 4 of mitochondrial respiration, respiratory control rate - RCR - and mitochondrial permeability ransition) ${ }^{20-21}$. 


\section{Statistical analysis}

The results were analyzed statistically by the nonparametric Mann-Whitney test, with the level of significance set at 5\% (P $<0.05)$. Statistical analyses were performed with the GraphPad Prism 4.0 software (GraphPad Software Inc, La Jolla, CA).

\section{Results}

Regarding the quantification of serum enzymes, a significant difference in AST levels was observed between the SHAM and HBOI/R groups and also between the I/R and HBOI/R groups (Figure 1A). There was also a significant difference in ALT levels between the SHAM and I/R groups (Figure 1B). There was no significant difference in other associations between groups.

The oxygen consumption rate in state 3 of mitochondrial respiration differed significantly between the SHAM group and the I/R and HBO/R groups (Figure $2 \mathrm{~A}$ ). The oxygen consumption rate in state 4 of mitochondrial respiration differed significantly between the I/R and HBO I/R groups (Figure 2B). RCR differed significantly between the SHAM and I/R groups (Figure 2C). Mitochondrial swelling was differed significantly between the SHAM group and the I/R and HBO I/R groups (Figure 2D). There was no significant difference in other associations between groups.

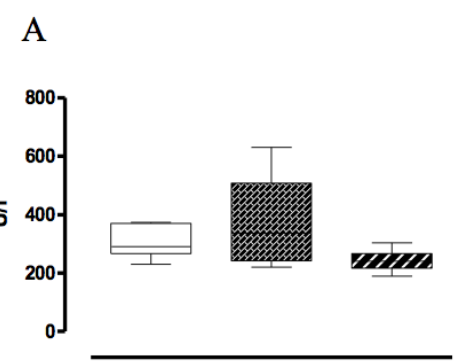

Legend:
B

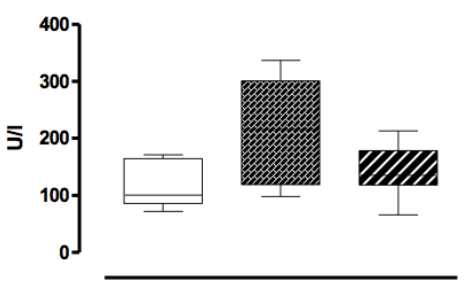

I/R
II. HBOI/R

FIGURE 1 - Serum enzymes: SHAM (rats submitted to surgical stress without exposure to Hyperbaric Oxygen Therapy - HBO - and without liver pedicle clamping), I/R (rats submitted to $30 \mathrm{~min}$ of ischemia followed by $5 \mathrm{~min}$ of reperfusion without exposure to HBO),and HBOI/R (rats submitted to $60 \mathrm{~min}$ of $\mathrm{HBO}$ at $2 \mathrm{ATA}$ and immediately submitted to $30 \mathrm{~min}$ of ischemia followed by $5 \mathrm{~min}$ of reperfusion). (A) Aspartate aminotransferase (AST): SHAM vs HBOI/R $(\mathrm{p}<0.05)$, I/R vs HBOI/R $(\mathrm{p}<0.05)$. (B) Alanine aminotranferase (ALT): SHAM vs $\mathrm{I} / \mathrm{R}(\mathrm{p}<0.05)$.

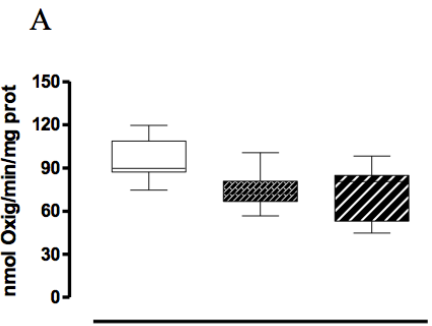

C

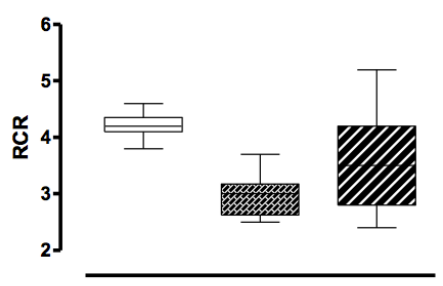

B

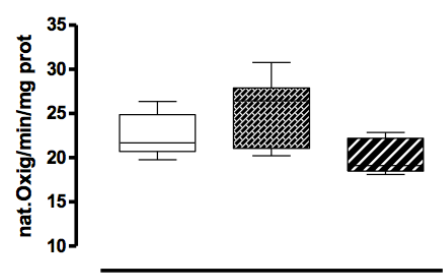

$\mathrm{D}$

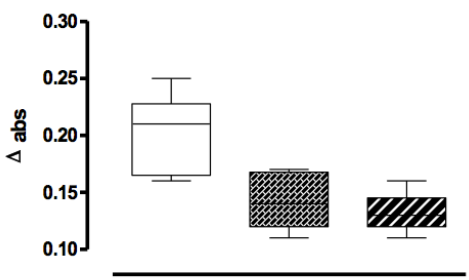

Legend:

SHAM

$\mathrm{I} / \mathrm{R}$

WH HBOI/R

FIGURE 2 - Hepatic mitochondrial function in the groups studied: SHAM (rats submitted to surgical stress without exposure to hyperbaric oxygen therapy - HBO - and without hepatic pedicle clamping), I/R (rats submitted to $30 \mathrm{~min}$ of ischemia followed by 5 min of reperfusion without exposure to HBO), and HBOI/R (rats submitted to $60 \mathrm{~min}$ of $\mathrm{HBO}$ at 2 ATA and immediately after submitted to $30 \mathrm{~min}$ of ischemia followed by 5 min of reperfusion). (A) State 3 of mitochondrial respiration: SHAM vs I/R $(\mathrm{p}<0.05)$; SHAM vs HBOI/R $(\mathrm{p}<0.05)$. (B) State 4 of mitochondrial respiration: I/R vs HBOI/R (p $<0.05$ ). (C) Respiratory Control Rate (RCR): SHAM vs I/R (p, 0.05). (D): Mitochondrial swelling: SHAM vs I/R (p, 0.05); SHAM vs HBOI/R (p <0.05.). 


\section{Discussion}

The injury caused by hepatic ischemia and reperfusion has been extensively quantified in the literature by measuring tissue parameters of mitochondrial function ${ }^{13,18}$ and serum ALT and $\operatorname{AST}^{6,11,16}$.

The energy produced by mitochondria can be assessed by studying respiration and mitochondrial membrane potential 13. In our study we assessed mitochondrial respiration through the oxygen consumption rate in state 4 (basal respiration), rate of oxygen consumption in state 3 (ADP-activated respiration) and RCR, which indicates the degree of coupling between oxygen uptake and ADP phosphorylation. Furthermore, the inner mitochondrial membrane permeability was measured by osmotic swelling of the mitochondria, related to $\mathrm{Ca} 2+$ homeostasis.

Regarding state 3 of mitochondrial respiration (Figure $2 \mathrm{~A}$ ), a decrease in oxygen consumption rate was observed in the $\mathrm{I} / \mathrm{R}$ group compared to the SHAM group $(\mathrm{p}<0.05)$. This shows a decrease in the ability of mitochondria to synthesize ATP, resulting in functional impairment in the group submitted to ischemia/ reperfusion, as also observed by other authors ${ }^{13}$. In our study, considering the oxygen consumption in state 3 of mitochondrial respiration, there was no significant difference between the group that underwent ischemia and reperfusion with or without exposure to $\mathrm{HBO}$. This result suggests that if there was exacerbation of oxidative stress by exposure to $\mathrm{HBO}$, this factor was not enough to aggravate liver mitochondrial injury under these conditions. If $\mathrm{HBO}$ promotes aerobic metabolism when preserving ATP reserves, these reserves, theoretically, reduce injury during the ischemic phase of the injury process due to ischemia/reperfusion. Under these experimental conditions, this protective effect is not sufficient to prevent damage to the mitochondrial membrane.

Regarding state 4 of mitochondrial respiration (Figure 2B), we observed an increase in oxygen consumption rate by mitochondria in the I/R group compared to the SHAM group $(\mathrm{p}<0.05)$ in order to maintain the proton electrochemical gradient of the mitochondrial membrane, making it suitable for ADP phosphorylation when necessary. This increase suggests an uncoupling between oxygen consumption and ADP phosphorylation, as well as an alteration in permeability of the inner mitochondrial membrane, in agreement with other literature reports ${ }^{13}$. In our study, hyperoxic preconditioning was effective regarding oxygen consumption in state 4 , without significant differences between the group submitted to HBO and the SHAM group. This result, in association with the analysis of state 3 parameters, suggests that exposure to $\mathrm{HBO}$ promoted a partial benefit for mitochondrial membrane preservation.
RCR analysis (Figure 2C) showed a significant difference between the I/R and SHAM groups ( $p<0.05$ ), with decreased RCR in group I/R. Hyperoxia was favorable to the maintenance of mitochondrial coupling, corroborating the results obtained in states 3 and 4 and showing preservation of mitochondrial function in the SHAM and HBOI/R groups.

Osmotic mitochondrial swelling induced by $\mathrm{Ca} 2+$ and phosphate (Figure 2D) was decreased in the $I / R$ and $H B O I / R$ groups compared to the SHAM group $(\mathrm{p}<0.05)$, showing that the induction was effective only for the SHAM group and that the mitochondria of groups $\mathrm{I} / \mathrm{R}$ and $\mathrm{HBOI} / \mathrm{R}$ were already swollen and therefore showed altered mitochondrial inner membrane permeability. It is possible that high levels of the oxygen supply before the induction of ischemia causes plasma to be full of this ROS-forming substrate, an inducer of lipid peroxidation. It is known that the vasoconstriction which occurs after vasodilation during the ischemic period is perpetuated in reperfusion ${ }^{22}$ and inhibited by HBO ${ }^{12}$. Probably within the first five minutes of reperfusion the time for this effect to occur efficiently was not sufficient and therefore mitochondrial membrane injury was not prevented. Further studies regarding the generation of reactive oxygen species and nitric oxide production may elucidate the possible causes of this change.

Mitochondrial swelling, as a rule, occurs due to the increased ion influx into the cell compartment which simultaneously increases the flow of water to this intracellular space. On this basis, we assume that the imbalance in osmotic regulation may result from oxidative damage with functional damage of membrane transporters or lack of ATP to carry out active transport of these ions.

Considering the oxygen consumption in state 4 of mitochondrial respiration, it is possible to assume that membrane structural changes in the HBOI/R group possibly consisted only of a transient change in membrane permeability, as demonstrated by the study of mitochondrial osmotic swelling. Regarding the decreased oxygen consumption in state 3 , there is evidence of a decreased rate of ATP synthesis.

Regarding serum ALT and AST values, it is known that their absolute values and/or the ALT/AST ratio may serve as indicators of hepatocellular integrity, with an association between increased serum levels of these enzymes and acute hepatic injury ${ }^{5-6}$.

In this experimental condition of $\mathrm{I} / \mathrm{R}$, there was no increase in serum AST levels (Figure 1A) as observed by other authors ${ }^{13}$. However, hyperoxic preconditioning was shown to be protective, with a significant difference between the $I / R$ and $\mathrm{HBOI} / \mathrm{R}$ groups, as also observed by other authors ${ }^{23}$. A significant 
difference was observed between the SHAM and HBOI/R groups, suggesting that stress caused by the surgical procedure could be mitigated by hyperoxic preconditioning through an increased systemic antioxidant response or through the action of inflammatory mediators on tissues sensitive to oxygen such as the lungs and liver, making injury more locoregional and less systemic. The hypothesis of antioxidant induction by HBO therapy has been raised by some authors ${ }^{24}$ and the hypothesis of redirection of inflammatory mediators can also be found in other studies ${ }^{12}$.

Serum ALT levels (Figure 1B) were increased in the I/R group compared to the SHAM group $(\mathrm{p}<0.05)$, in consonance with other studies in the literature $5,6,25$. Our study shows that hyperoxic preconditioning is hepatoprotective, reducing the total level of this enzyme to levels close to those of the SHAM group. This result is scientifically conflicting since some authors have suggested that the $\mathrm{HBO}$ and $\mathrm{I} / \mathrm{R}$ association is positive ${ }^{24}$ while others claim it to be negative, suggesting that previous exposure to $\mathrm{HBO}$ would cause an increase in ALT levels ${ }^{11}$.

\section{Conclusion}

Immediately after reperfusion, hyperbaric oxygen therapy attenuates the damage of liver ischemic/reperfusion injury in the rat.

\section{References}

1. Tibbles PM, Edelsberg JS. Hyperbaric oxygen therapy. N Engl J Med.1996;334:1642-8. http://dx.doi.org/10.1056/ NEJM199606203342506Similares

2. Nylander G, Nordström H, Lennart Franzén L, Henriksson $\mathrm{KG}$, Larsson J. Effects of hyperbaric oxygen treatment in postischemic muscle: A quantitative morphological study. Scand J Plast Reconstr Surg Hand Surg. 1988;22:31-9. http://dx.doi. org/10.3109/02844318809097932

3. Chen MF, Chen HM, Ueng SW, Shyr MH. Hyperbaric oxygen pretreatment attenuates hepatic reperfusion injury. Liver. 1998;18:110-6. http://dx.doi.org/10.1111/j.1600-0676.1998. tb00135.x

4. Losada DM, Jordani ME, Jordani MC, Piccinato MA, Fina CF, Feres O, Chies AB, Evora PR, de Castro E Silva O. Should preconditioning hyperbaric oxygenarion protect the liver against ischemiareperfusion injury? An experimental study in a rat model. Transplant Proc. 2014;46(1):56-62. doi: 10.1016/j.transproceed.2013.10.044.

5. Ramachandran S, Liaw JM, Jia J, Glasgow SC, Liu W, Csontos K, Upadhya GA, Mohanakumar T, Chapman WC. Ischemiareperfusion injury in rat steatotic liver is dependent on $\mathrm{NF \kappa B}$ P65 activation. Transpl Immunol. 2012;26:201-6. http://dx.doi. org/10.1016/j.trim.2012.01.00

6. Kanoria S, Glantzounis G, Quaglia A, Dinesh S, Fusai G, Davidson BR, Seifalian AM. Remote preconditioning improves hepatic oxygenation after ischaemia reperfusion injury. Transpl Int. 2012;25(7): 783-91. http://dx.doi.org/10.1111/j.14322277.2012.01481.x.

7. Miranda LEC, Viaro F, Ceneviva R, Évora PRB. As bases experimentais da lesão por isquemia e reperfusão do fígado: revisão. Acta Cir Bras. 2004;19:3-12. http://dx.doi.org/10.1590/S010286502004000100001

8. Teoh NC, Farrell GC. Hepatic ischemia reperfusion injury: pathogenic mechanisms and basis for hepatoprotection. J Gastroenterol Hepatol. 2003;18:891-902. http://dx.doi.org/ 10.1046/j.1440-1746.2003.03056.x

9. Castro-Silva O, Sankarankutty AK, Martinelli AL, Souza FF, Teixeira AC, Feres O, Mente ED, Oliveira GR, Akita R, Muglia V, Elias J Jr, Ramalho LN, Zucoloto S. Therapeutic effect of hyperbaric oxygen in hepatic artery thrombosis and functional cholestasis after orthotopic liver transplantation. Transplant Proc. 2006;38:1913-7. http://dx.doi.org/10.1016/j.transproceed.2006.06.062

10. Kihara K, Ueno S, Sakoda M, Aikou T. Effects of hyperbaric oxygen exposure on experimental hepatic ischemia reperfusion injury: relationship between its timing and neutrophil sequestration. Liver Transpl. 2005;11:1574-80. http://dx.doi.org/10.1002/lt.20533

11. Lima CX, Sanches MD, Rezende Neto JB, Oliveira e Silva RC, Teixeira MM, Souza DG, Santos GC, Melo Jr. Hyperbaric oxygen therapy aggravates liver reperfusion injury in rats. Acta Cir Bras. 2008;23:31521. http://dx.doi.org/10.1590/S0102-86502008000400004

12. Zamboni WA, Roth AC, Russell RC, Graham B, Suchy H, Kucan JO. Morphologic analysis of the microcirculation during reperfusion of ischemic skeletal muscle and the effect of hyperbaric oxygen. Plas Reconstr Surg. 1993;91:1110-23.

13. Castro-Silva O, Sankarankutty AK, Correa RB, Ferreira J, Vollet Filho JD, Kurachi C, Bagnato VS. Autofluorescence spectroscopy in liver transplantation: preliminary results from a pilot clinical study. Transplant Proc. 2008;40:722-5. http://dx.doi.org/10.1016/j. transproceed.2008.03.005

14. Thom SR. Hyperbaric oxygen therapy. J Intensive Care Med.1989;4:58-74.http://dx.doi.org/10.1177/088506668900400204

15. Thom SR. Hyperbaric oxygen: its mechanisms and efficacy. Plast Reconstr Surg, 2011;127:131-41. http://dx.doi.org/10.1097/ PRS.0b013e3181fbe2bf

16. Tandara AA, Mustoe TA. Oxygen in wound healing -- more than a nutrient. World J Surg. 2004;28:294-300. http://dx.doi.org/10.1007/ s00268-003-7400-2

17. Jung S, Wermker K, Poetschik H, Ziebura T, Kleinheinz J. The impact of hyperbaric oxygen therapy on serological values of vascular endothelial growth factor (VEGF) and basic fibroblast growth factor (bFGF). Head Face Med. 2010;6:29. http://dx.doi. org/10.1186/1746-160X-6-29

18. Tolentino EC, Castro-Silva O, Zucoloto S, Souza ME, Gomes MC, Sankarankutty AK, Oliveira GR, Feres O. Effect of hyperbaric oxygen on liver regeneration in a rat model. Transplant Proc. 2006;38:194752. http://dx.doi.org/10.1016/j.transproceed.2006.06.066

19. Henry RJ, Chiamori N, Golub OJ, Berkman S. Revised spectrophotometric methods for the determination of glutamicoxalacetic transaminase, glutamic-pyruvic transaminase, and lactic dehydrogenase. Am J Clin Pathol. 1960;34:381-98.

20. Souza ME, Polizello AC, Uyemura SA, Castro-Silva o, Curti C. Effect of fluoxetine on rat liver mitochondria. Biochem Pharmacol. 1994;48:535-41. http://dx.doi.org/10.1016/0006-2952(94)90283-6

21. Jordani MC, Santos AC, Prado IM, Uyemura SA, Curti C. Flufenamic acid as an inducer of mitochondrial permeability transition. Mol Cell Biochem. 2000;210:153-8. http://dx.doi. org/10.1023/A:1007185825101

22. Nanobashvili J, Neumayer C, Fuegl A, Blumer R, Prager M, Sporn E, Polterauer P, Malinski T, Huk I. Development of 'no-reflow' phenomenon in ischemia/reperfusion injury: failure of active vasomotility and not simply passive vasoconstriction. Eur Surg Res. 2003;35:417-24. http://dx.doi.org/10.1159/000072226 
23. Yu SY, Chiu JH, Yang SD, Yu HY, Hsieh CC, Chen PJ, Lui WY, Wu CW. Preconditioned hyperbaric oxygenation protects the liver against ischemia-reperfusion injury in rats. J Surg Res. 2005;128:2836. http://dx.doi.org/10.1016/j.jss.2005.04.025

24. Özden TA, Uzun H, Bohloli M, Toklu AS, Paksoy M, Simsek G, Durak H, Issever H, Ipek T. The effects of hyperbaric oxygen treatment on oxidant and antioxidant levels during liver regeneration in rats. Tohoku J Exp Med. 2004;203:253-65. http://dx.doi. org/10.1620/tjem.203.253

25. Centurion SA, Centurion LM, Souza ME, Gomes MC, Sankarankutty AK, Mente ED, Castro e Silva O. Effects of ischemic liver preconditioning on hepatic ischemia/reperfusion injury in the rat. Transplant Proc. 2007;39:361-4. http://dx.doi.org/10.1016/j. transproceed.2007.01.011

\section{Correspondence:}

Orlando de Castro e Silva Jr

Faculdade de Medicina de Ribeirão Preto-USP

Departamento de Cirurgia e Anatomia, $9^{\circ}$ andar

Campus Universitário, Monte Alegre

14048-900 Ribeirão Preto - SP Brasil

orlandojr@usp.br.

Financial source: Sao Paulo Research Foundation (FAPESP)

${ }^{1}$ Research performed at Department of Surgery and Anatomy, Ribeirao Preto Medical School-USP and LIM 37, Department of Gastroenterology of Medical School, Faculty of Medicine, Sao Paulo University (FMUSP), Brazil. 